
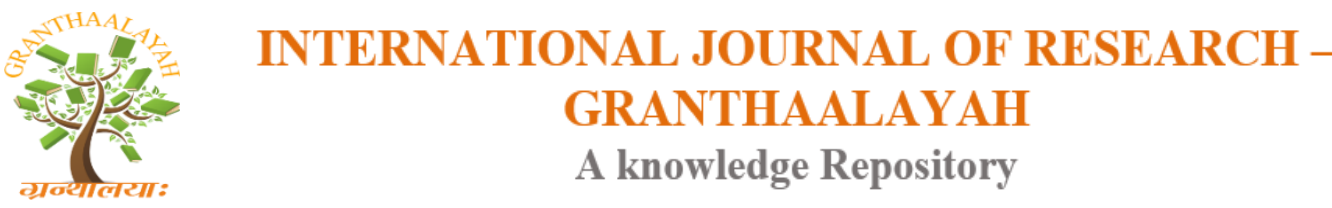

Science

\title{
PERFORMANCE ANALYSIS OF A CONVENTIONAL AIR HEATER
}

\author{
Gade Bhavani Shankar ${ }^{* 1}$, P.S.Kishore ${ }^{2}$ \\ *1, 2 Department of Mechanical, Engineering, College of Engineering (A.) Andhra University, \\ Visakhapatnam, Andhra Pradesh, India
}

DOI: https://doi.org/10.29121/granthaalayah.v5.i4.2017.1826

\begin{abstract}
Solar energy constitutes one of the main alternatives for facing the energy problems of the future. Solar air heaters are used for applications at low and moderate temperatures. Such as crop drying, timber seasoning, space heating, and drying agriculture products. Artificial geometry applied on the absorber plate is the very efficient method to improve thermal performance of solar air heaters. The thermal efficiency of solar air heaters is generally poor due to low heat transfer coefficient between the absorber plate and air flowing in the collector. Thermal performance of the conventional solar air heater was studied under varying solar and ambient conditions in different months. At day time the solar heating system stored the thermal solar energy as sensible and latent heat. A parametric study was done for 10 months for the climatic conditions of Visakhapatnam. The effect of change in the tilt angle, length and breadth of a collector and mass flow rate on the temperature of collector has been studied. The length of the collector is $2.1 \mathrm{~m}$ and width of the collector is $1.1 \mathrm{~m}$. the performance analysis of system shows potential of improving the thermal efficiency range is $31 \%$ to $47 \%$.From the obtained results, graphs are drawn to assess the performance analysis of a conventional air heater.
\end{abstract}

Keywords: Solar Radiation; Useful Heat Gain; Heat Removal Rate; Mass Flow Rate.

Cite This Article: Gade Bhavani Shankar, and P.S.Kishore. (2017). "PERFORMANCE ANALYSIS OF A CONVENTIONAL AIR HEATER." International Journal of Research - Granthaalayah, 5(4), 320-333. https://doi.org/10.29121/granthaalayah.v5.i4.2017.1826.

\section{Introduction}

Solar air heaters are devices that utilize solar radiation for a variety of purposes. These devices are simple and can be constructed inexpensively. Mainly, solar air heaters consist of a transparent cover, an absorber plate and insulation material. The air flow enters through the channel that is formed by the absorber plate and the transparent cover. Solar radiation absorbed by the absorber plate. The absorbed heat transferred to the air as it flows along the channel increases its temperature. This heated air can be used in several applications such as drying 
agricultural products, space heating and air conditioning, water heating and industrial process heating.

The efficiency of solar air heaters can be affected by various parameters such as collector length, number of channels, depth of channels, type of absorber plate, number and material of glass covers, air inlet temperature and air velocity. All of these parameters and their effects on the efficiency of solar air heaters will be discussed below.

Several researchers discussed performance of different types of conventional air heater used for different purposes.

Paraschiv et al. [1] in their paper have done a present contribution describes the investigation of a solar air collector for space heating "Various configurations of absorber and different air flows through the collector were tested. The influence of the air mass flow on the air outlet temperature and thermal efficiency has been studied. The thermal efficiency, fluid outlet temperature, heat increase and heat losses of the collector are calculated depending on the collector geometry, fluid properties, fluid inlet temperature, air flow rate, solar insulation and ambient temperature.

Eshan and Kishore [2] in their paper evaluation of various parameters of a compound parabolic collector have analyzed a compound parabolic collector for Visakhapatnam location.

Enibe [3] in their paper have done a transient thermal analysis of a natural convection solar air heater is presented. The predicted performance of the system is compared with experimental data under daytime no-load conditions over the ambient temperature range of $19-41{ }^{\circ} \mathrm{C}$ and daily global irradiation of 4.9-19.9 MJ m-2. Predicted temperatures at specific locations on the absorber plate, heat exchanger plate, glazing, and heated air agree closely with experimental data to within $10,6,8$, and $10^{\circ} \mathrm{C}$, respectively. Maximum predicted cumulative useful and overall efficiencies of the system are within the ranges $2.5-13$ and $7.5-18 \%$, respectively. Correlations of the predicted efficiencies are presented.

Kurtbas and Durmus [4] in their paper have designed a new solar air heater .In their study they used five solar collectors with dimensions of $0.9 \times 0.4 \mathrm{~m}$ and the flow line increased where it had narrowed and expanded geometrically in shape. These collectors were set to four different cases with dimensions of $1 \times 2 \mathrm{~m}$. In this study they found that the efficiency of the collector enhances with the increase of mass flow rates due to an enhanced heat transfer to the air flow and also increase in efficiency depends on the surface geometry of the collector and extension of the air flow line. Collector efficiency, temperature difference of the air and pressure loss is the more important parameters in order to decrease the energy loss.

Ucar and Inalli [5] in their article have worked on the solar air collectors with passive augmentation techniques using energetic analysis. In order to provide better heat transfer surfaces suitable for the passive heat transfer augmentation techniques different shape and arrangement of absorber surfaces of the collectors were reorganized.. It has been found that the efficiency of solar collector has been increased approximately $10 \%$ to $30 \%$ as compared with the conventional solar collector using the passive techniques. In conventional solar air heater, only a 
little part of solar energy absorbed by the collector can be used therefore the performance of the conventional solar air heater was found to be least.

Esen [6] in their article have worked on the energy and energy analysis of a novel flat plate solar air heater $(\mathrm{SAH})$ with and without obstacles. The experiments were carried out at different values of mass flow rate of air and different levels of absorbing plates in flow channel duct. The measured parameters were solar radiation and temperatures at different state of points such as inlet, outlet, at the absorbing plate and the ambient. it was also found that the double-flow collector supplied with obstacles $(60.97 \%$, for $0.025 \mathrm{~kg} / \mathrm{s}$ and State II) were better than that of without obstacles $(25.65 \%$, for $0.015 \mathrm{~kg} / \mathrm{s}$ and State I).

Alta et al [7] in their paper have investigated the energy and energy efficiency of three different types of solar air heaters, two having fins and one without fins besides one heaters with fins has single glass cover while the other two have double glass cover. The energy and energy output rates of the solar air heaters were evaluated at different air flow rates viz. 25, 50 and $100 \mathrm{~m} 3 / \mathrm{m} 2$ $\mathrm{h}$, tilt angle at $0^{\circ}, 15^{\circ}$ and $30^{\circ}$ and temperature conditions versus time. While transparent cover decreases convection heat losses, fins obtain more heat because of an increase in the heating time by circulating air inside process.

Panwar et al. [8] in their article have reviewed the literature on energy and energy analyses of solar drying systems and suggested that for utilizing low grade energy to dry agricultural produces solar drying is the promising option. It is the property of the system, which gives the maximum power that can be obtained from the system when it is brought to a thermodynamic equilibrium state from a reference state. The energy used in drying of agricultural and industrial produce is significant and, therefore, represents an often reducible element of process cost.

\section{Description and Working of a Conventional Air Heater}

\subsection{General Description on SAH}

Conventional solar air heater consists of a flat plate collector with an absorber plate, transparent cover system at the top and insulation at the bottom and on the sides. Whole assembly is enclosed in a sheet metal container. Working fluid is air and the passage for its flow varies according to the type of air heater. Materials for the construction of air heater are similar to the liquid flat plate collectors. Transmission of solar radiation through the cover system and its subsequent absorption in the absorber plate can be taken into account by expressions identical to those of liquid flat-plate collectors. In order to improve collection efficiency, selective coating on the absorber plate can be used. 


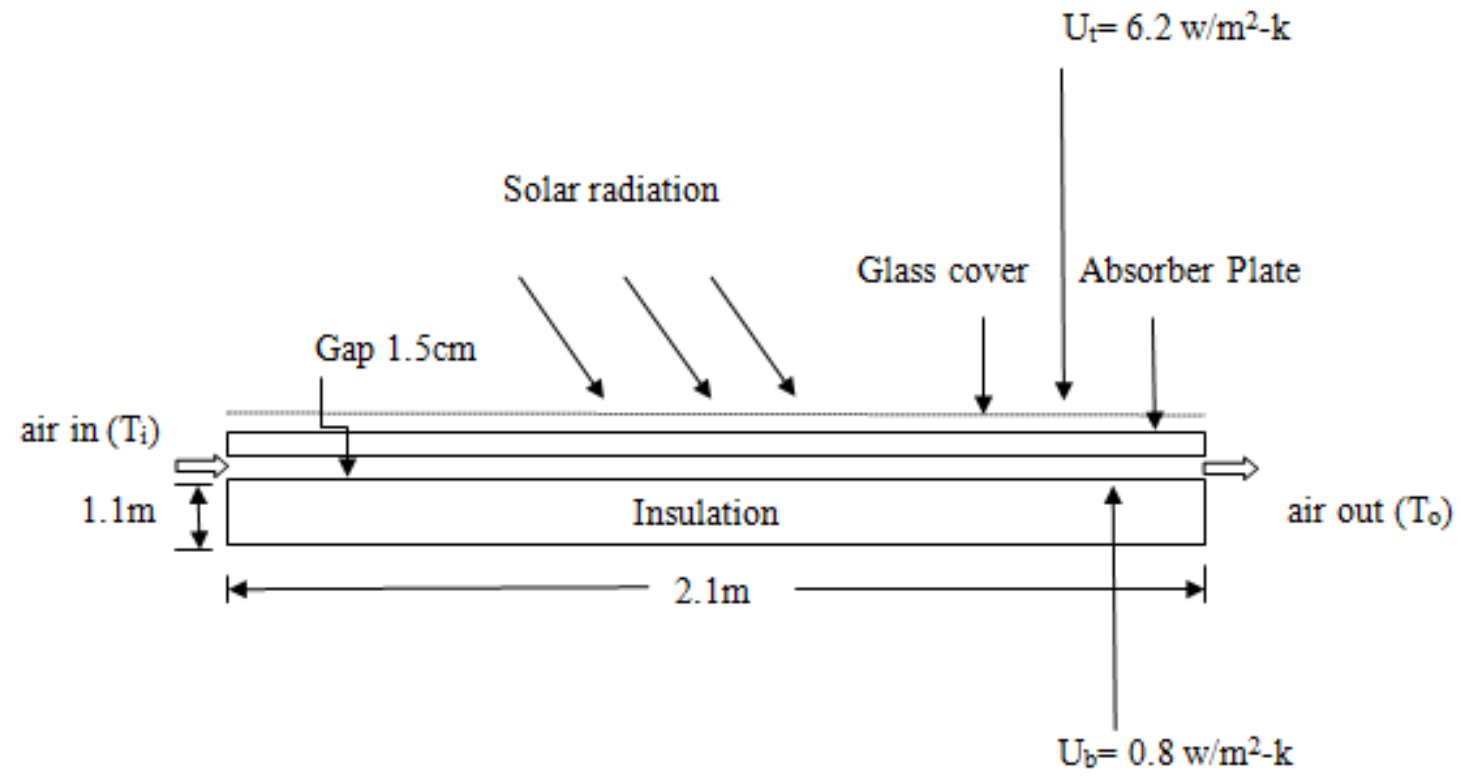

Figure 1: conventional solar air heater

\subsection{Components of Solar Air Heaters}

\subsubsection{Absorber Plate}

The absorber plate should have high thermal conductivity, adequate tensile and compressive stre1ngth, and good corrosion resistance. Copper is generally preferred because of its extremely high conductivity and resistance to corrosion. Collectors are also constructed with aluminum, steel, Galvanized Iron (GI) sheets and various thermoplastics and metal ions. Standard procedure for fabricating an absorber plate is to take a sheet of metal (like copper or aluminium) and insulate the non-flow surface depending on type of solar air heater. Solar radiation absorbed by this metal sheet would heat it and some of the heat is transferred to air. This hot air is used for the practical applications.

\subsubsection{Cover Plate}

Cover plate or plates through which the solar energy must be transmitted is also extremely important part of solar air heater. Purposes of cover plates are

1) to transmit as much as solar energy as possible to the absorber plate

2) to minimize the loss from the absorber plate to the environment

3) to shield the absorber plate from direct exposure to weathering

The most important requirements of cover plate-materials are strength, durability, nondegradability, and solar energy transmission. Glass is the most common cover material for collectors. Tempered glass has more durability than other glasses and resists thermal cycling. In selecting the glass for cover plates, mechanical strength must be adequate to resist breakage from the maximum expected wind and snow loads. Mechanical strength is proportional to the square 
of the thickness of the glass. Cover plates for solar collectors nominally should be at least $0.33 \mathrm{~cm}$ thick.

Thermal shock to glass cover plate also is taken into account. Several different processes cause it. For example day-by-day heating and cooling caused by variation in solar intensity on the collectors during the morning hours and subsequent decrease in the afternoon. Again in cloudy conditions, glass temperatures can rise and fall by 50 degrees or more in a matter of minutes as clouds pass overhead. Central area of the collectors is subjected to greater heating than edges. This results in thermal stress, which can cause breakage of glass covers.

\subsubsection{Insulation}

Insulation is used to prevent loss of heat from the absorber plate due to conduction or convection. Usual insulating materials are rock wool or glass wool. Absorber plate should be insulated beneath and or in the side, depending on the type of design used. Important requirement of an insulator is that it should be heat resistant.

\subsection{Applications of Solar Air Heater}

It is technically feasible to use solar heated air for providing energy for almost any application that uses solar-heated liquids. The important areas of applications are the following.

\subsubsection{Space Heating and Cooling of Buildings}

The solar energy collectors are generally the air heaters or flat-plate liquid collectors for converting solar radiation into heat. In most of the solar space heating systems, the temperature requirement of the fluid is in the range of 50 to $80^{\circ} \mathrm{C}$, which makes the system much simpler. Space heating is of particular relevance in colder countries where significant amount of energy is required for this purpose

\subsubsection{Drying and Curing of Agricultural Products}

A cabinet-type solar dryer, is suitable for small scale use. The dryer consists of an enclosure with a transparent cover. Material to be dried is placed on perforated trays. The absorber inside the dryer absorbs solar radiation entering the enclosure. This leads to the heating of air surrounding the absorber. The hot air is circulated through the perforated trays. As a result the moisture is removed from the product. Suitable openings at the bottom and top ensure a natural circulation. A temperature ranging from 50 to 80 degrees is usually attained, and the drying time ranges from 2 to 4 days. For large-scale drying, natural circulation is replaced by forced circulation. Solar dryer is a very useful device for

1) Agriculture crop drying

2) Food processing industries for dehydration of fruits, potatoes, onions and other vegetables,

3) Dairy industries for production of milk powder, casein etc.

4) Seasoning of wood and timber.

5) Textile industries for drying of textile materials. 


\subsubsection{Industrial Applications}

Use of solar air heaters for industrial application is gaining momentum in these days. In timber industry, hot air is used for seasoning timber. In the case of plastic sector, solar air heaters are used for curing of plastics. Another application is the regeneration of dehumidifying agents. In industries solar air heaters are attached to industrial application on the basis of industrial cogeneration. Use of solar air heaters in industrial sector is fast increasing.

\subsection{Instrument for Measuring Solar Radiation}

The instruments for measuring solar radiation are pyranometer or a pyreheliometer. A pyranometer is an instrument which measures either global or diffuse radiation falling on a horizontal surface over a hemispherical field of view. Basically the pyranometer consists of a black surface which heats up when exposed to solar radiation. Its temperature increases until the rate of heat gain by solar radiation equals the rate of heat loss by convection, conduction and radiation. The hot junction of a thermopile is attached to the black surface, while the cold junctions are located under a guard plate so that they do not receive the radiation directly. As a result an emf is generated. This emf which is usually in the range of 0 to $10 \mathrm{mV}$ can be read, recorded or integrated over a period of time and is a measure of the global radiation. An accuracy of about 2 percent can be obtained with the instrument. The pyranometer can also be used for the measurement of diffuse radiation. This is done by mounting it at the centre of a semicircular shading ring. The shading ring is fixed in such a way that its plane is parallel to the plane of the path of the sun's daily movement across the sky and it shades the thermopile element and the two glass domes of the pyranometer at all times from direct sunshine. Consequently, the pyranometer measures only the diffuse radiation received from the sky. A pyreheliometer is an instrument which measures beam radiation falling on a surface normal to the sun's rays.

\section{Analysis of Conventional Solar Air Heater}

\section{Solar Radiation on Tilted Surfaces}

\subsection{Beam Radiation}

For the case of a tilted surface facing south $\left(\gamma=0^{0}\right)$.

$\operatorname{Cos} \theta=\sin \delta \sin (\phi-\beta)+\cos \delta \cos \omega \cos (\phi-\beta)$

While for a horizontal surface

$\operatorname{Cos} \theta z=\sin \phi \sin \delta+\cos \phi \cos \delta \cos \omega$

$r_{b}=\frac{\cos \theta}{\cos \theta_{z}}=\frac{\sin \delta \sin (\varnothing-\beta)+\cos \delta \cos \omega \cos (\emptyset-\beta)}{\sin \emptyset \sin \delta+\cos \emptyset \cos \delta \cos \omega}$

\subsection{Diffuse Radiation}

$r_{d}=(1+\cos \beta) / 2$

Since $(1+\cos \beta) / 2$ is the radiation shape factor for a tilted surface with respect to the sky. 


\subsection{Reflected Radiation}

$$
r_{r}=\rho(1-\cos \beta) / 2
$$

Since $(1-\cos \beta) / 2$ is the radiation shape factor for the surface with respect to the surrounding ground.

\subsection{Flux on Tilted Surface}

The flux $I_{T}$ falling on a tilted surface at any instant is thus given by $I_{T}=I_{b} r_{b}+I_{d} r_{d}+\left(I_{b}+I_{d}\right) r_{r}$

\subsection{The declination $\delta$}

The angular displacement of the sun from the place of the earth's equator is termed as the declination of the sun is given by the equation

$\delta($ in degrees $)=23.45 \sin \left[\frac{360}{365}(284+n)\right]$

\subsection{The hour angle $\omega$}

$=\cos ^{-1}(-\tan \emptyset \tan \delta)$

\subsection{Hourly Global, Beam and Diffuse Radiation under Cloudless Skies}

Flux absorbed in the absorber plate

$S=I_{b} r_{b}(\tau \alpha)_{b}+\left(I_{d} r_{d}+\left(I_{b}+I_{d}\right) r_{r}\right)(\tau \alpha)_{d}$

\subsection{Fluid means temperature}

$$
\mathrm{T}_{\mathrm{f}}=\mathrm{T}_{\mathrm{i}}+\mathrm{T}_{\mathrm{a}} / 2
$$

3.9. Heat transfer coefficient inside the tube

$$
\mathrm{R}_{\mathrm{e}}=\frac{\rho \mathrm{vd}}{\mu}
$$

\subsection{Nusselt no}

$$
N_{u}=0.0158 R e^{0.8}
$$

\subsection{Collector efficiency factor $\left(F^{\prime}\right)$}

$$
F^{\prime}=\left(1+\frac{U_{l}}{h_{e}}\right)
$$


3.12. Collector heat - removal factor $\left(F_{R}\right)$

$$
=\frac{m C_{P}}{U_{1} A_{P}}\left[1-\exp \left\{-\frac{F^{\prime} U_{1} A_{p}}{m C_{p}}\right\}\right]
$$

\subsection{Useful heat gain $\left(q_{u}\right)$}

$$
\mathrm{q}_{\mathrm{u}}=\mathrm{F}_{\mathrm{R}} \mathrm{A}_{\mathrm{p}}\left[S-\mathrm{U}_{1}^{\prime \prime}\left(\mathrm{T}_{\mathrm{fi}}-\mathrm{T}_{\mathrm{a}}\right)\right]
$$

\subsection{Thermal efficiency $(\eta)$}

The instantaneous efficiency can be calculated on the basis of beam radiation

$$
\eta=\frac{q_{u}}{A_{a} \times I_{b}}
$$

\section{Results and Discussions}

A conventional solar air heater was analyzed for Visakhapatnam location and graphs are plotted different results are plotted based on different parameters such as solar flux, efficiency, heat transfer coefficient, useful heat gain rate, pressure drop and heat removal factor.

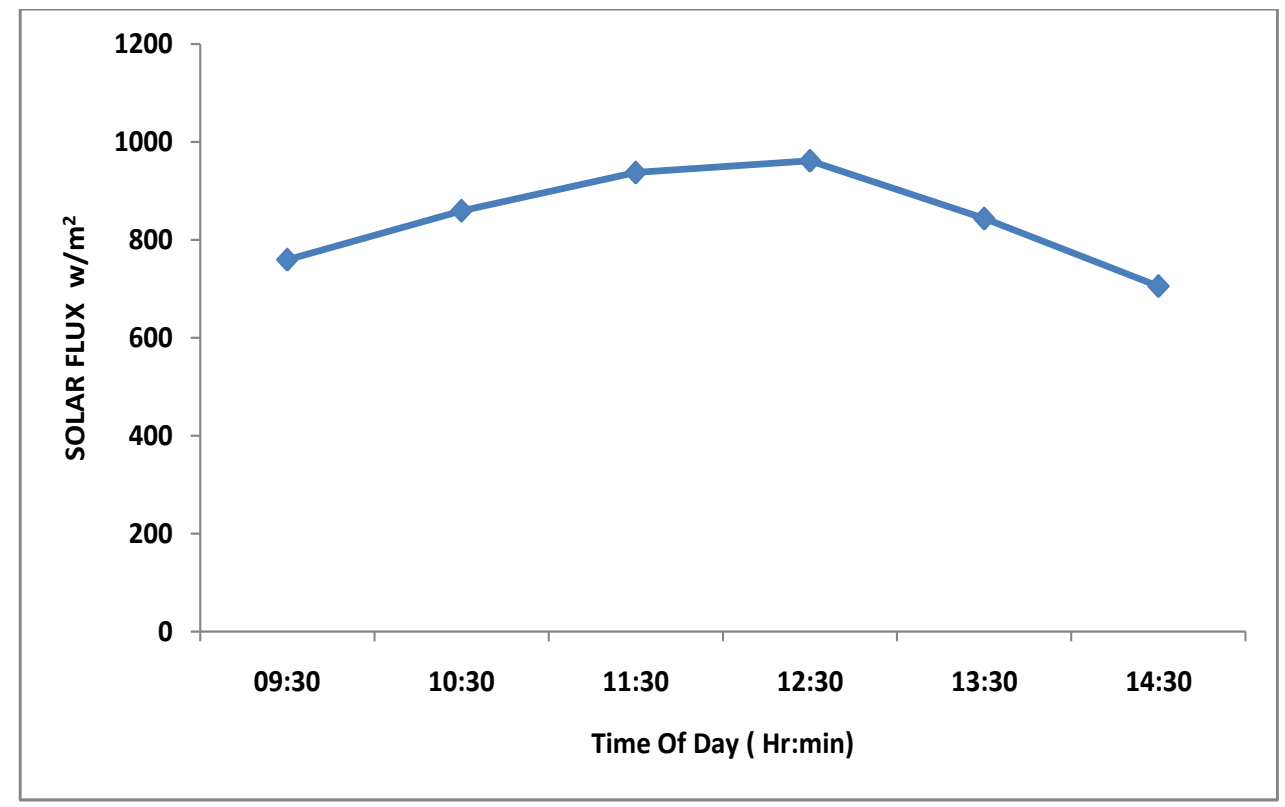

Figure 2: Hourly variation of solar intensity at Visakhapatnam

Figure 2 shows the hourly variation of solar intensity over Visakhapatnam on May 08. The Solar intensity at $09: 30 \mathrm{AM}$ is $759 \mathrm{~W} / \mathrm{m} 2$ it increases up to $937 \mathrm{~W} / \mathrm{m}^{2}$ at $12: 30 \mathrm{PM}$ then it decreases to $705 \mathrm{~W} / \mathrm{m}^{2}$ at $14: 30 \mathrm{hrs}$. From the graph we can conclude that solar intensity is Maximum at around 12:30 PM. 


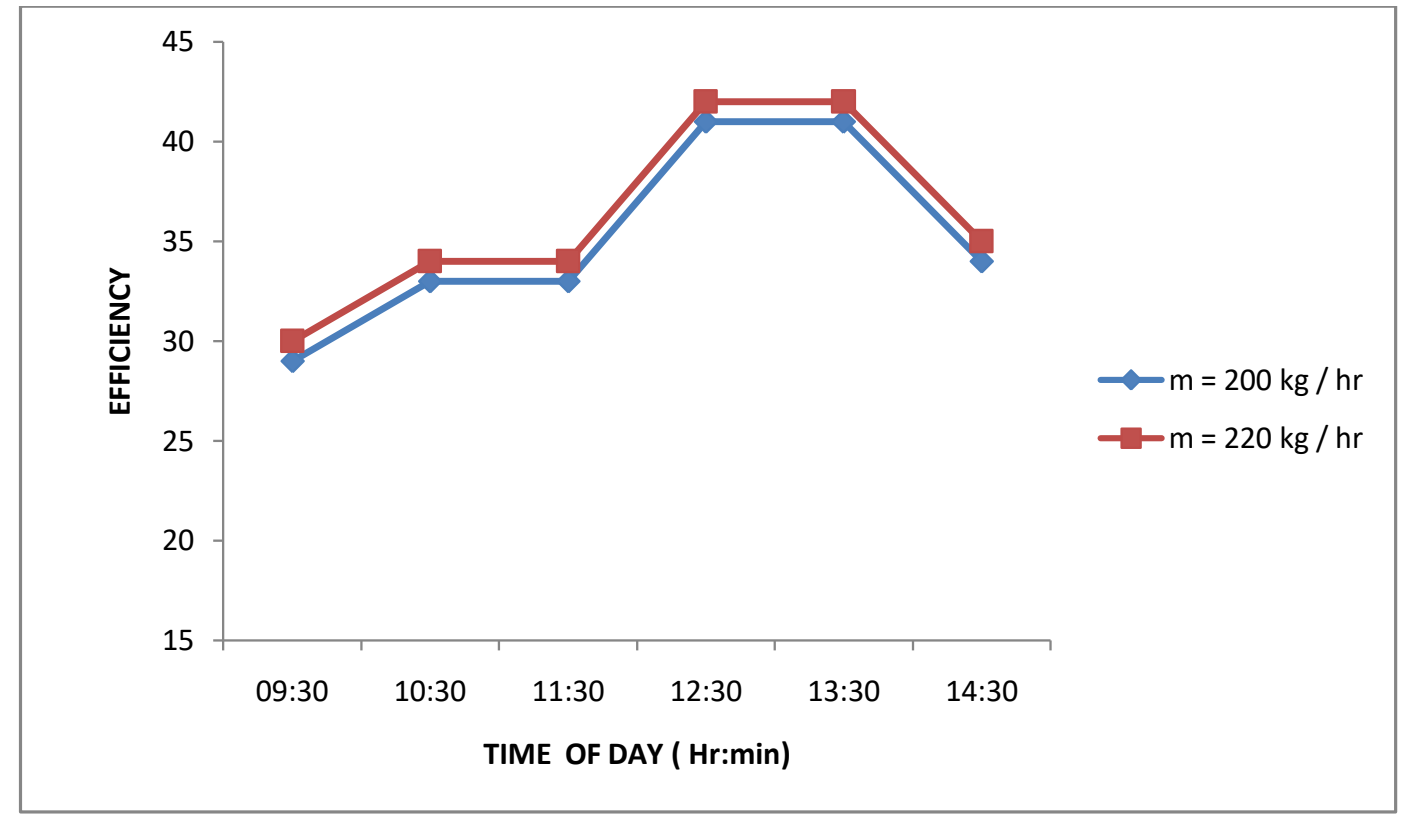

Figure 3: Variation of Efficiency at different mass flow rates at Visakhapatnam

Figure 3: show the variation of efficiency at different mass flow rates. The results show the Efficiency curves at mass flow rates of $200 \mathrm{~kg} / \mathrm{hr}$ and $220 \mathrm{~kg} / \mathrm{hr}$. It is observed that the collector has increased efficiency at a flow rate of $220 \mathrm{~kg} / \mathrm{hr}$. from this graph we can conclude that the mass flow rate increase the efficiency also increases..

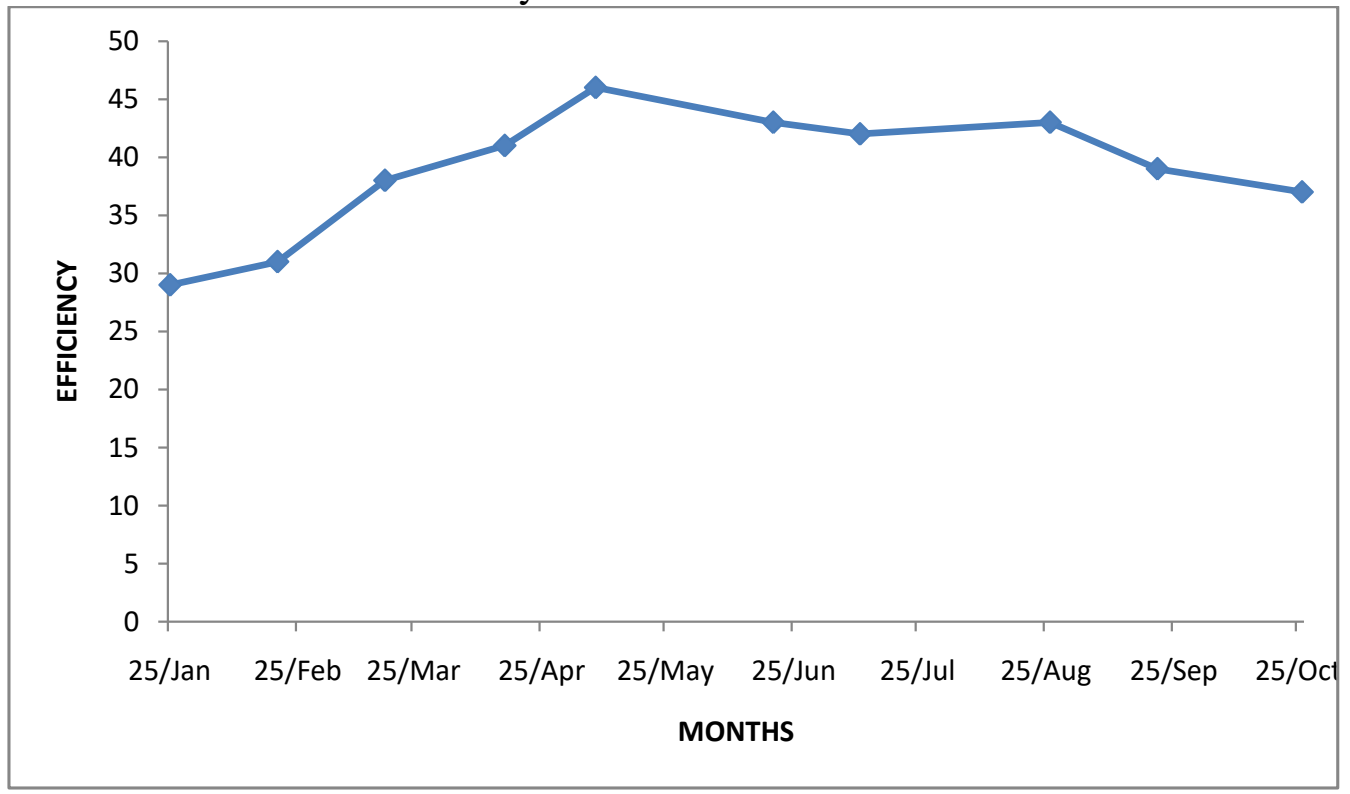

Figure 4: Variation of Efficiency air heater in Visakhapatnam

Figure 4 shows the variation of Efficiency in Visakhapatnam for a period of ten months from January 2016 to October 2016. The efficiency varies from $31 \%$ to $47 \%$ from this graph we can infer that the maximum efficiency occurred in May month. 


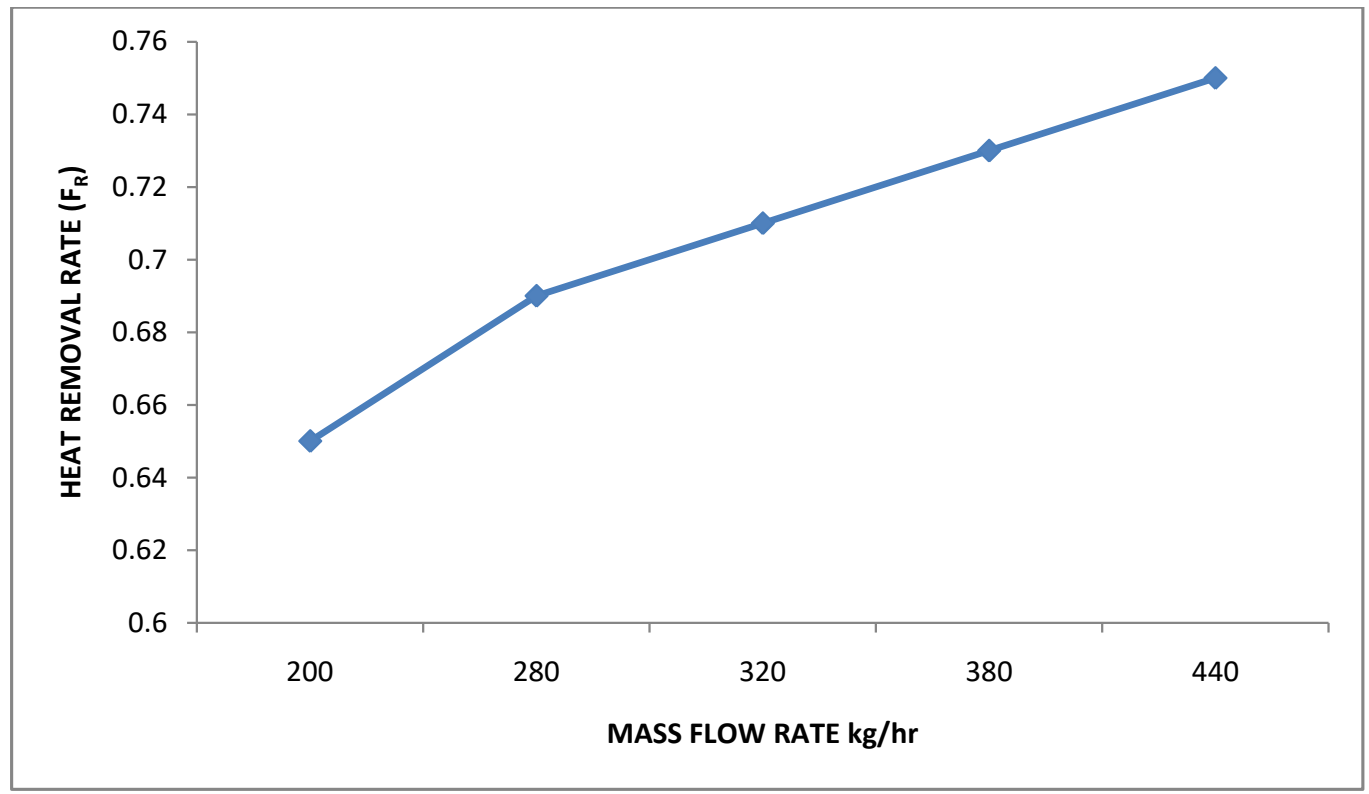

Figure 5: Variation of heat removal factor with mass flow rate

Figure 5 The above graph shows the variation of mass flow rate and heat removal factor. The results obtained show that with increase in mass flow rate from $200 \mathrm{~kg} / \mathrm{hr}$ to $440 \mathrm{~kg} / \mathrm{hr}$.the heat removal factor also increases from 0.65 to 0.75 .

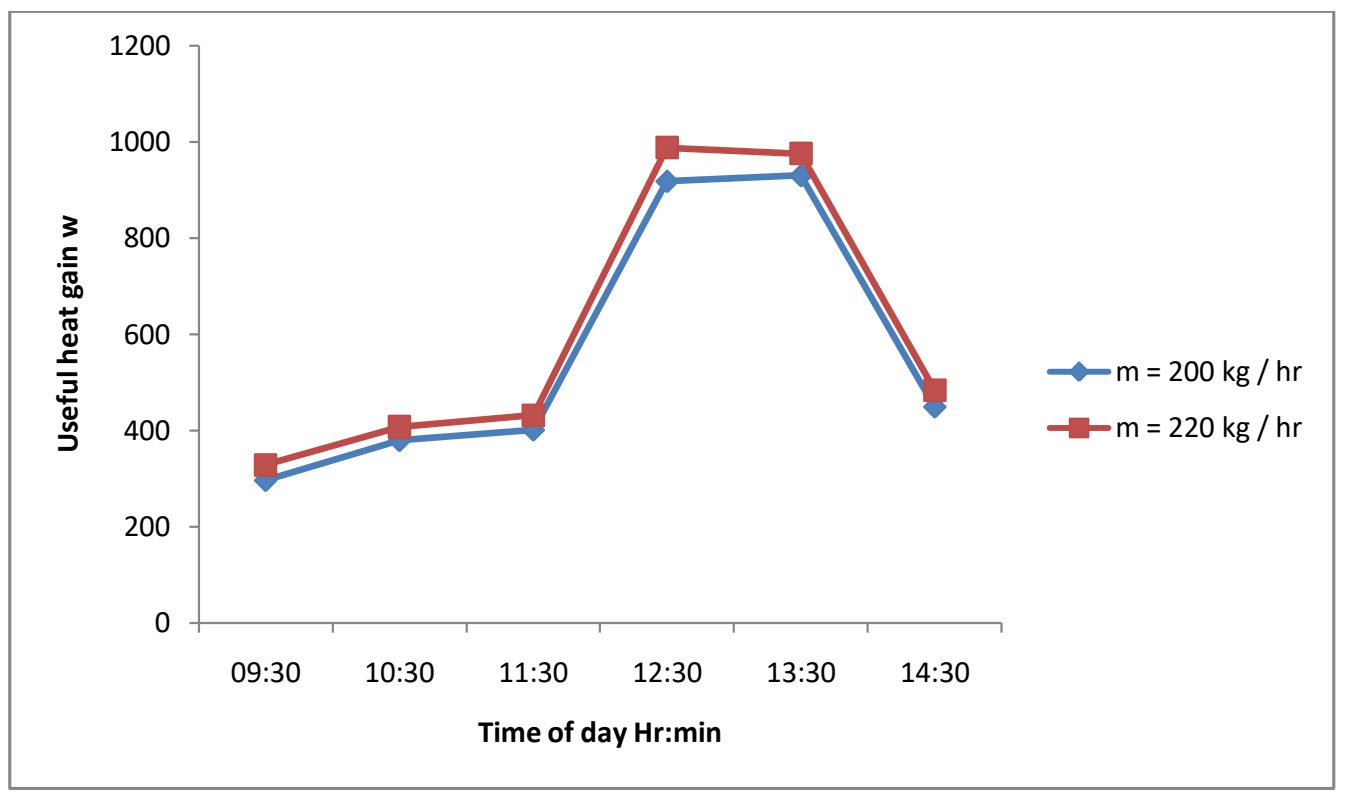

Figure 6: Variation of useful heat gain rate throughout the day at different mass flow rates

Figure 6 shows the variation of useful heat gain rate on 8 May at mass flow rates of $200 \mathrm{~kg} / \mathrm{hr}$ and $220 \mathrm{~kg} / \mathrm{hr}$. From the results thus obtained we can infer that maximum heat gain rate is around noon when the solar intensity is high, also at a higher mass flow rate the rate of useful heat gain is also high. 


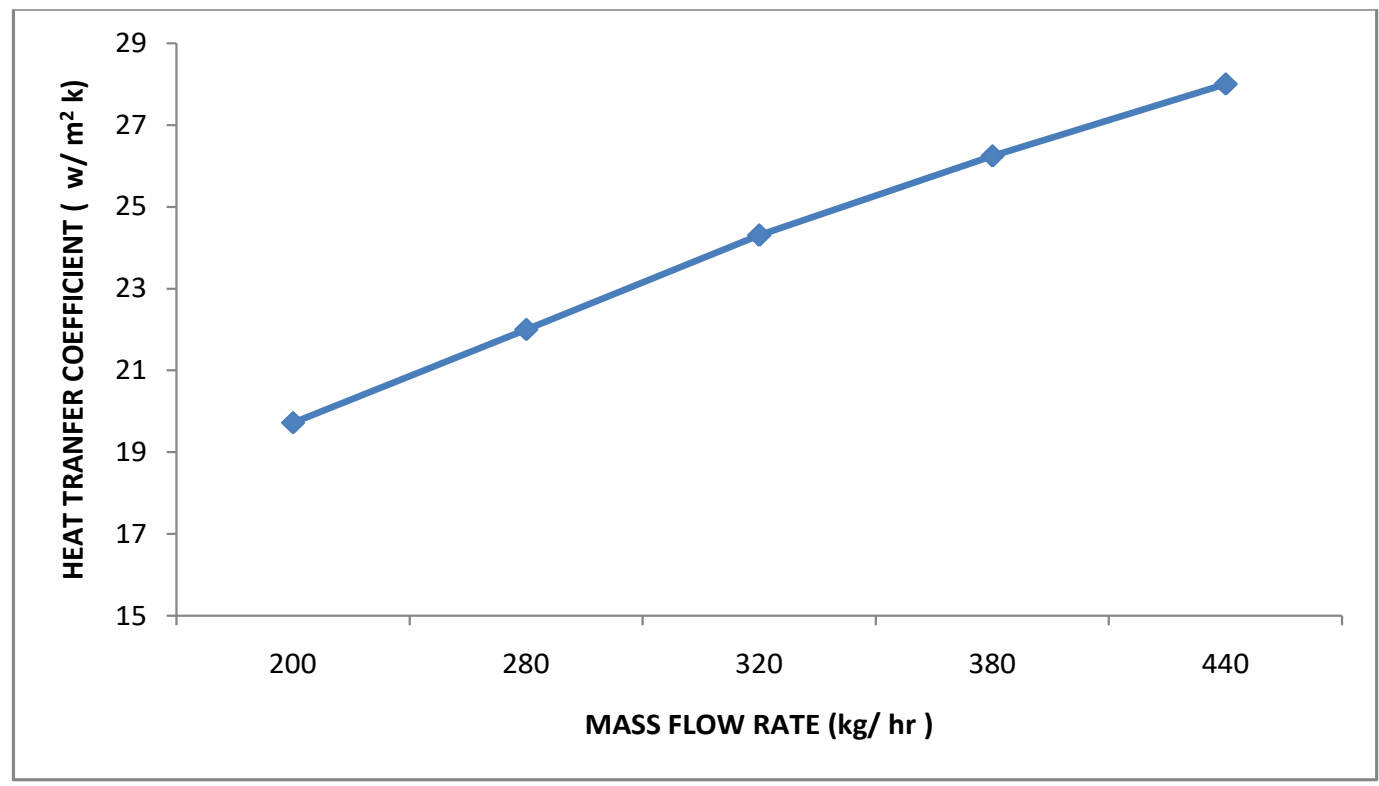

Figure 7: Variation of Heat transfer coefficient to mass flow rate.

Figure 7 shows that variation of heat transfer coefficient with mass flow rate. And the results obtained show that with increase in mass flow rate from $200 \mathrm{~kg} / \mathrm{hr}$ to $440 \mathrm{~kg} / \mathrm{hr}$ heat Transfer coefficient also increases from $19 \mathrm{~W} / \mathrm{m} 2 \mathrm{~K}$ to $28.5 \mathrm{~W} / \mathrm{m} 2 \mathrm{~K}$ for Visakhapatnam. Therefore it is clear that heat transfer coefficient increases with increase in mass flow rate due to increase in temperature difference.

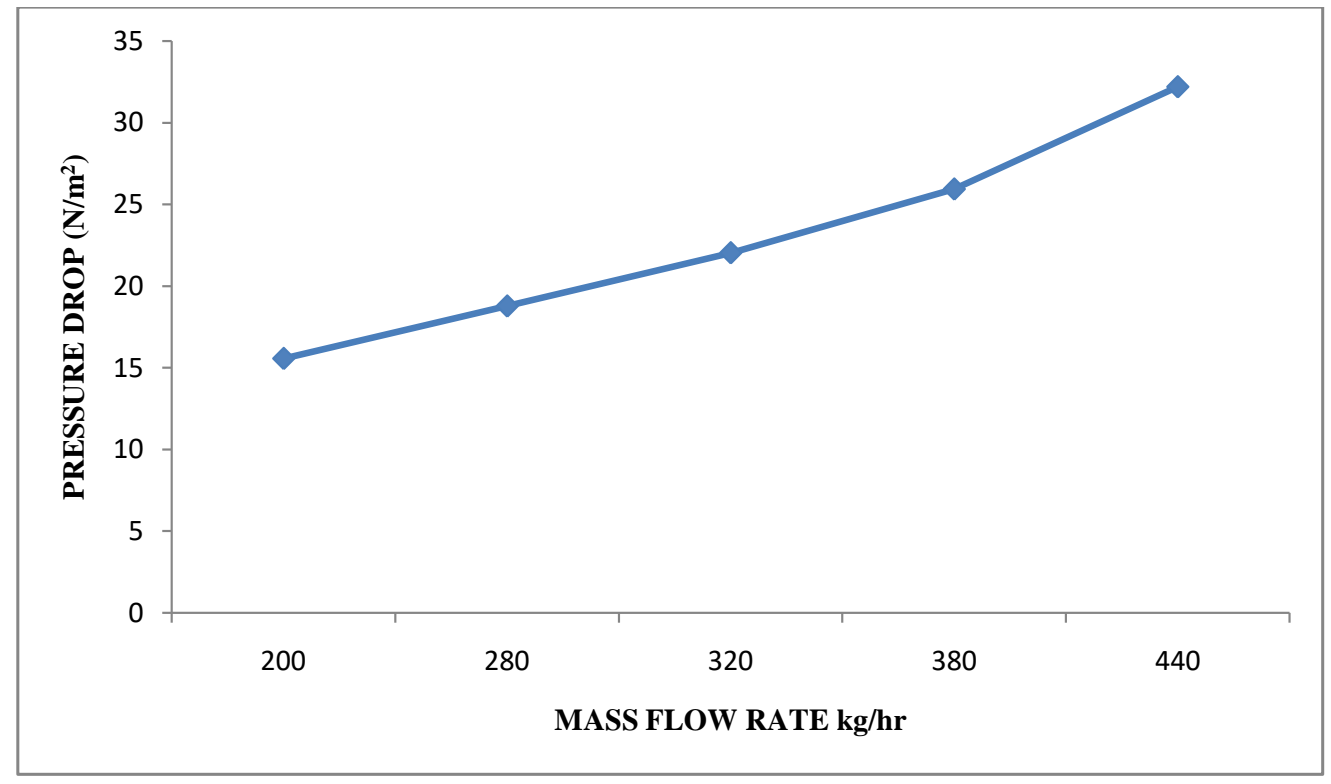

Figure 8: Variation of mass flow rate to Pressure drop

Figure 8 shows that variation of mass flow rate with pressure drop. And the Results obtained show that with increase in mass flow rate from $200 \mathrm{~kg} / \mathrm{hr}$ to $440 \mathrm{~kg} / \mathrm{hr}$ Pressure drop also increases from $15.57 \mathrm{~N} / \mathrm{m}^{2}$ to $32.20 \mathrm{~N} / \mathrm{m}^{2}$ for Visakhapatnam. Therefore it is clear that pressure drop increases with increase in mass flow rate. 
The conventional solar air heater was analyzed for the city of Visakhapatnam and accordingly graphs were plotted from the obtained results.

\section{Conclusion}

From the performance evaluation done on the conventional solar air heater it can be concluded that the analyzed conventional solar air heater worked reasonably well for buildings and agriculture purpose at atmospheric pressure.

From the comparison of conventional solar air heater at Visakhapatnam following conclusions can be drawn.

1) The values of collector solar flux $\left(\mathrm{I}_{\mathrm{T}}\right)$ and plate efficiency factor $(\mathrm{F})$ both increase at higher rate with increase of solar radiation.

2) The efficiency of the solar air heater is almost similar while varying the mass flow rates. It increases by $2 \%$ for 20 units increase in mass flow rate.

3) Solar radiation and ambient temperature can be recognized as the dominate factors influence the performance of the conventional solar air heater thermal efficiency of the collector increase as the solar radiation and ambient temperature increase. The thermal efficiency of the heater increase with increasing flow velocity and its average value reaches at $75 \%$.

4) The heat removal rate varies almost linearly with the mass flow rate.

5) The useful heat gain rate of the air heater for a day shows that air heater has maximum useful heat gain rate at noon.

6) The heat transfer coefficient increases with mass flow rate (due to increase in temperature difference). The heat transfer coefficient increases by $50 \%$ by varying the mass flow rate.

Such solar air heaters are useful for space heating of the building and for sustainability of agriculture purpose.

\section{Nomenclature}

$\begin{array}{ll}\text { Symbol } & \text { Description } \\ \mathrm{A}_{\mathrm{c}} & \text { area }\left(\mathrm{m}^{2}\right) \\ \mathrm{A}_{\mathrm{P}} & \text { area of the absorber plate }\left(\mathrm{m}^{2}\right) \\ \mathrm{C}_{\text {air }} & \text { specific heat of air }\left(\mathrm{J} / \mathrm{kg}^{\circ} \mathrm{C}\right) \\ \mathrm{d}_{\mathrm{e}} & \text { equivalent diameter }(\mathrm{m}) \\ \mathrm{f}^{\prime} & \text { collector efficiency factor } \\ \mathrm{f}_{\mathrm{R}} & \text { collector heat removal factor } \\ \mathrm{h} & \text { heat transfer coefficient }\left(\mathrm{w} / \mathrm{m}^{2} \mathrm{k}\right) \\ \mathrm{h}_{\mathrm{bf}} & \text { convective heat transfer between bottom and fluid }\left(\mathrm{w} / \mathrm{m}^{2}{ }^{\circ} \mathrm{c}\right) \\ \mathrm{h}_{\mathrm{e}} & \text { effective heat transfer coefficient }\left(\mathrm{w} / \mathrm{m}^{2}{ }^{\circ} \mathrm{c}\right) \\ \mathrm{I} & \text { intensity of solar radiation }\left(\mathrm{w} / \mathrm{m}^{2}\right) \\ \mathrm{m} & \text { air mass flow rate }(\mathrm{kg} / \mathrm{s}) \\ \mathrm{n} & \text { day of year } \\ \mathrm{N}_{\mathrm{u}} & \text { Nusselt number } \\ Q_{\mathrm{u}} & \text { useful heat gain rate of the collector }(\mathrm{w}) \\ \mathrm{P}_{\mathrm{r}} & \text { prandlt no }\end{array}$




$\begin{array}{ll}\mathrm{q} & \text { heat gain rate } \\ \mathrm{R}_{\mathrm{e}} & \text { Reynolds number } \\ \mathrm{T}_{\mathrm{a}} & \text { ambient temperature }\left({ }^{\circ} \mathrm{C}\right) \\ \mathrm{T}_{\mathrm{bm}} & \text { mean bottom plate temperature }\left({ }^{\circ} \mathrm{C}\right) \\ \mathrm{T}_{\mathrm{f}} & \text { fluid temperature }\left({ }^{\circ} \mathrm{C}\right) \\ \mathrm{T}_{\mathrm{i}} & \text { inlet air temperature }\left({ }^{\circ} \mathrm{C}\right) \\ \mathrm{T}_{\mathrm{o}} & \text { oultet air temperature }\left({ }^{\circ} \mathrm{C}\right) \\ \mathrm{T}_{\mathrm{pm}} & \text { mean plate temperature }\left({ }^{\circ} \mathrm{C}\right) \\ \mathrm{U}_{\mathrm{b}} & \text { bottom loss coefficient }\left(\mathrm{W} / \mathrm{m}^{2 \circ} \mathrm{C}\right) \\ \mathrm{U}_{\mathrm{L}} & \text { overall heat loss coefficient of the collector }\left(\mathrm{W} / \mathrm{m}^{2}{ }^{\circ} \mathrm{C}\right) \\ \mathrm{U}_{\mathrm{t}} & \text { top loss coefficient }\left(\mathrm{W} / \mathrm{m}^{2}{ }^{\circ} \mathrm{C}\right) \\ \mathrm{U}^{\prime} & \text { loss coefficient }\left(\mathrm{w} / \mathrm{m} 2{ }^{\circ} \mathrm{C}\right)\end{array}$

\section{Greek symbols}

$\alpha$

$\beta$

$\delta$

$\varepsilon$

$\eta$

$\mu$

$\omega$

$\psi$

$\rho$

$\tau$

\section{Subscripts}

a

c

e

$f_{o}$

$f_{i}$

$f_{m}$

i

1

o

$\mathrm{u}$

\section{References}

[1] Lizica Simona Paraschiv, Spiru Paraschiv, Ion V.Ion Experimental And Theoretical Analyses On Thermal Performance Of A Solar Air Collector. Environmental Engineering And Management Journal.Vol.13, Issue No.8, pp 1965-1970, 2014.

[2] Eshan Kumar Nashine And P.S.Kishore" Thermal Analysis Of A Compound Parabolic Collector" International Journal Of Engineering Research.”Vol.6, Issue No.1, pp 24-29,2017.

[3] Enibe S.O.. Performance Of A Natural Circulation Solar Air Heating System With Phase Change Material Energy Storage. Renewable Energy, Vol.27, pp69-86,2002 absorptivity of absorber surface

the slope

the declination angle

emissivity

efficiency

viscosity $\left(\mathrm{N} \mathrm{s} / \mathrm{m}^{2}\right)$

hour angle

the latitude

transmissivity of glass cover density $\left(\mathrm{kg} / \mathrm{m}^{3}\right)$ 
[4] Kurtbas I., Durmus A. Efficiency And Energy Analysis Of A New Solar Air Heater, Renewable Energy, Vol.29, pp1489-1501, 2004.

[5] Ucar A., Inallı M. Thermal And Energy Analysis Of Solar Air Collectors With Passive Augmentation Techniques. International Communications In Heat And Mass Transfer, Vol.33, pp1281-1290, 2006.

[6] Esen H. (2008). Experimental Energy And Energy Analysis Of A Double-Flow Solar Air Heater Having Different Obstacles On Absorber Plates. Building And Environment, Vol.43, pp 10461054, 2008.

[7] Alta D., Bilgili E., Ertekin C., Yaldiz O. Experimental Investigation Of Three Different Solar Air Heaters: Energy And Energy Analyses. Applied Energy, Vol.87, pp2953-2973,2010.

[8] Panwar N.L., Kaushik S.C., Kothari S. A Review On Energy And Energy Analysis Of Solar Dying Systems. Renewable And Sustainable Energy Reviews, Vol.16, pp2812- 2819, 2012

*Corresponding author.

E-mail address: gadebhavani26@gmail.com 